\title{
Strategies to include sexual orientation and gender identity in health professions education
}

\author{
A Müller, Dr med \\ Gender Health and Justice Research Unit, Faculty of Health Sciences, University of Cape Town, South Africa
}

Corresponding author: A Müller (alexandra.muller@uct.ac.za)

Background. Sexual orientation and gender identity are not taught in African health professions curricula. In order to improve the quality of care for lesbian, gay, bisexual, transgender and intersex (LGBTI) patients, health professionals need to shift their attitudes towards sexual orientation and gender identity, and learn about specific LGBTI health needs.

Discussion. The curricula of African health professions education provide various opportunities to include teaching about sexual orientation and gender identity. Various disciplines can teach sexual orientation and gender identity issues in their context by challenging heteronormativity and highlighting specific LGBTI health concerns, and can do so more successfully with interactive teaching approaches that hold more potential than formalised lectures. Rights-based teaching frameworks should include sexual orientation and gender identity as markers of difference. To achieve this, educators need to build capacity to teach about these issues, and support LGBTI students in their institutions.

Conclusion. Teaching about sexual orientation and gender identity is urgently needed in African health professions education, but it is complex. This article presents strategies to incorporate sexual orientation and gender identity into the curricula of medical schools, nursing colleges, and the allied health sciences.

Afr J Health Professions Educ 2015;7(1):4-7. DOI:10.7196/AJHPE.359

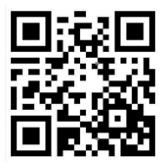

Social justice and equity are important principles in African health sciences education, leading to awareness of the social and economic determinants of health among our graduates. However, more forces of exclusion exist than our current curricula recognise. In this article, I review the health consequences of the social exclusion of lesbian, gay, bisexual, transgender and intersex (LGBTI) people. I then present a curricular framework for educators who are interested in teaching about sexual orientation and gender identity. A recent curricular review at the University of Cape Town's Faculty of Health Sciences revealed profound gaps in teaching about sexual orientation and gender identity. ${ }^{[1]}$ There is no evidence that the curricula at other South African (SA) or African health education institutions are significantly different.

Sexual orientation and gender identity are not health hazards per $s e$, but the social exclusion of LGBTI people leads to significant health disparities. Homophobia, the irrational fear and hatred of LGBTI people, and heteronormativity, a social construct that makes LGBTI identities invisible and assumes that heterosexual relationships are the norm, are powerful constructs that have direct and indirect impact on LGBTI people's health. As a marginalised group, and compared with heterosexual peers, LGBTI people experience higher levels of depression, suicide and substance abuse, and are at higher risk for sexually transmitted diseases, including $\mathrm{HIV}^{[2]}$ Because of mistrust in the health system, LGBTI people are less likely to utilise health promotion services, e.g. gynaecological cancer screenings, and are therefore at higher risk for non-communicable diseases. ${ }^{[3]}$ Current SA health policies recognise that transgender people, as well as men who have sex with men, are particularly vulnerable populations. ${ }^{[4]}$ Nevertheless, LGBTI people continually experience discrimination, harassment, and even denial of care by healthcare professionals. ${ }^{[5,6]}$ In countries where legislation penalises homosexuality or homosexual behaviour, LGBTI people may even risk arrest when seeking healthcare. Homophobia continues to be a problem in medicine worldwide, ${ }^{[7]}$ and it is important to note that it not only decreases the quality of care for LGBTI patients, but also marginalises LGBTI health professionals.

The above-mentioned factors make a compelling argument for the need to teach our health professionals about sexual orientation and gender identity, in order to challenge their attitudes and behaviours, and to equip them with knowledge relevant to LGBTI patients. ${ }^{[2]}$ Training in health professions education is a formative experience for future doctors, nurses and allied health professionals. In order to educate non-discriminatory professionals, it is imperative that their experiences include sufficient opportunities to learn about sexual orientation and gender identity, the healthcare needs of LGBTI people, and ways to provide such care in a compassionate and nonjudgmental manner.

\section{Opportunities for teaching about sexual orientation and gender identity}

There are many opportunities for teaching about sexual orientation and gender identity in health professions curricula (Table 1). Among these are first and foremost patient-provider interaction training, but also clinical subjects and contact with health professionals in the field. These professionals can model appropriate care and interest in LGBTI patients, mentor LGBTI students, and conduct research on LGBTI health-related issues. Sexual orientation and gender identity cannot and should not be taught in one specific course, but rather be spiralled through the curriculum to enable students to challenge their own attitudes, and learn about specific LGBTI health issues and the psychosocial well-being of LGBTI people.

Courses that endeavour to develop students' skills in patient-provider interactions are a key opportunity to challenge students' attitudes and equip them with knowledge to care for LGBTI patients. Aspects of sexual orientation and gender identity should be included when discussing professional behaviour with students, with an emphasis on the ethical 


\section{Forum}

Table 1. Sexual and gender minority health content in health professions courses

\begin{tabular}{ll}
\hline Course & Potential LGBTI content \\
\hline Patient-provider & Discuss professional behaviour and non-judgmental care with \\
interaction & regard to sexual orientation and gender identity \\
training & Address students' attitudes towards non-heteronormative \\
& identities \\
& Include LGBTI patients, or patients with same-sex partners in case \\
& studies and patient-provider communication exercises \\
& History-taking: Teach gender-neutral language ('partner' instead \\
& of 'wife/husband', etc.) \\
& Taking sexual histories: Include information about sexual \\
& orientation, gender identity and non-heteronormative sexual \\
& practices
\end{tabular}

Human biology Discuss sexual orientation and gender identity as part of

and development physiological psychosocial development

Public health Use rights-based frameworks to address sexual orientation and and primary gender identity with regard to:

healthcare

- Access to healthcare

- Social determinants of health

- Health disparities

Paediatrics

Discuss gender behaviour and gender norms

Discuss the difference between sexual orientation and gender identity in sexual development case studies

Discuss the impact of homophobia, family and peer pressure on adolescent mental health

\section{Educational outcomes}

Awareness of sexual and gender minority identities, heteronormativity, trans- and homophobia as impacting on access to healthcare Recognition of professional standards and conduct of care with regard to sexual and gender minorities

Ability to provide culturally competent, non-judgmental care to sexual and gender minority patients

Awareness of sexual and gender minority identities

Understanding of development and influences on sexual orientation and gender identity

Understanding of sexual orientation and gender identity as social determinants of health

Ability to assess the social context and health risk factors of sexual and gender minority patients

Knowledge of health disparities and the impact of discrimination and social exclusion

Understanding of development and influences on sexual orientation and gender identity

Ability to differentiate between biological sex and socially constructed gender, and assess sociocultural impact of the latter

Understanding of the impact of discrimination and social exclusion on the health of teenage sexual and gender minority patients Ability to provide clinically competent care to young sexual and gender minority patients

Knowledge about specific health concerns for lesbian and bisexual women

Ability to provide clinically competent care to sexual and gender minority patients

- Little uptake of preventative services, including cancer screenings

- Higher risks of sexual violence, and subsequent HIV/ STI risks Discuss health prevention needs of transgender men

Psychiatry Discuss the historical pathologisation of LGBTI identities and impact thereof

Address the psychological impact of social and internalised homophobia

Discuss mental health risks of sexual and gender minority patients

Discuss sexual and gender minority patients' experience of violence and health consequences

Urology Discuss health prevention needs of gay men and transgender women

Infectious diseases Include epidemiological information about HIV prevalence among men who have sex with men

Discuss adequate prevention methods for people engaging in non-heteronormative sex

Understanding of historical context and resulting barriers to care for sexual and gender minority patients

Ability to provide clinically competent care to sexual and gender minority patients

Ability to provide clinically competent care to sexual and gender minority patients

Ability to provide clinically competent care to sexual and gender minority patients

obligation to provide care without judgment. Courses that address diversity offer a chance to talk about difference based on sexual orientation and gender identity. Case studies and student exercises can encourage students to think outside of the heteronormative paradigm, e.g. by including an
LGBTI patient, or a patient's same-sex partner with whom students need to communicate. When students learn to take patient histories, they can be engaged by conducting a sensitive and thorough sexual history that includes ways to ask about sexual orientation and gender identity. Teaching students 
to frame questions in a non-heteronormative manner will help them to identify their own assumptions and biases about sexual behaviour. ${ }^{[8]}$ Furthermore, they will learn about sexual practices beyond the scope of 'traditional' heterosexual behaviour, which will in turn enable them to give adequate information to LGBTI patients.

Issues of sexual orientation and gender identity are likely to arise in a number of medical disciplines. The teaching presented in these disciplines should build on the introductory information about sexual orientation and gender identity from the early years. Clinical educators play a key role in reminding students to ask questions about sexuality in a non-heteronormative and non-judgemental way, and can shift passive to active learning by asking students to work on issues of sexual orientation and gender identity within a particular case. It is imperative that discussions around sexual orientation and gender identity refrain from judgemental or moral characterisations, and rather focus on the challenges that LGBTI people encounter in contexts of homophobia and heteronormativity. The following section presents opportunities to teach sexual orientation and gender identity in human biology, public health and primary healthcare, paediatrics, obstetrics/gynaecology, psychiatry and infectious disease.

Courses in human biology and human development offer a good opportunity for an introduction to sexual orientation and gender identity. The advantage of these courses is that they reach a large student audience, and put sexual orientation and gender identity in the context of normal psychosexual development. Furthermore, they are usually in the early years of health professions education, and bring LGBTI visibility and attitudinal change to students' attention from the beginning. Of concern is that the information on sexual orientation and gender identity in these lectures may be dated or inaccurate, and that students will not be able to engage as much with the content in formalised lectures and seminars. Including sociologists/ anthropologists in an interdisciplinary team might be a helpful pedagogical approach.

Discussions of social determinants of health, barriers to accessing healthcare, and health disparities, taught in public health and primary healthcare, offer the opportunity to include an analysis based on sexual orientation and gender identity. LGBTI people face significant barriers when accessing care in public health facilities, and often avoid seeking care out of fear of homophobic treatment. ${ }^{[9]}$ A rights-based framework can address sexual orientation and gender identity when discussing non-discriminatory care, and can be reinforced by the Patient Rights Charter ${ }^{[10]}$ and Batho Pele Principles $^{[11]}$ (in SA, or relevant documents in other African countries), and professional codes of conduct.

Paediatrics and adolescent medicine can address gender behaviour and gender norms, which are often associated with sexual orientation. Children who present with gender atypical behaviour provide an opportunity to discuss gender identity issues and the distinction between sexual orientation (sexual and emotional attraction) and gender identity (one's sense of being male or female). This can be deepened when teaching about sexual development and puberty. Discussing the role of parental and peer pressure in conforming to gender norms can contribute to shape an understanding of the experiences of long-standing depression and poor self-esteem frequently expressed by LGBTI youth.

Obstetrics/gynaecology, with its focus on women's health, offers opportunities to teach about lesbian health. Lesbian women seek routine breast and cervical cancer screening less often than heterosexual women, might have higher risks for endometrial and ovarian cancer, and their providers underestimate their risk of cervical cancer. ${ }^{[2]}$ In SA, lesbian women are at a high risk of experiencing sexual violence, which places them at higher risk for contracting sexually transmitted diseases, including HIV ${ }^{[12]}$ These topics can be included to address the current lack of awareness of these issues.

Some of the many topics suitable for psychiatry are the history of pathologisation of LGBTI identities and the psychological impact of societal and internalised homophobia as well as LGBTI people's experiences of violence. These topics can be explored with the help of local LGBTI organisations, who are usually willing to provide testimony of LGBTI experiences for students, and facilitate direct interaction with LGBTI individuals.

The HIV prevalence among SA men who have sex with men is estimated to be $13 \%^{[13]}$ and the self-reported HIV prevalence among lesbian and bisexual women is $10 \%{ }^{[12]}$ Including this information in infectious disease courses will make students aware that LGBTI people are at high risk, and can teach them about prevention methods that are relevant to LGBTI people.

\section{Challenges to implementation}

Health professions education exists in a wider societal and cultural context. ${ }^{[14]}$ Despite overwhelming evidence of precolonial non-heterosexual identities, ${ }^{[15]}$ existing homophobic attitudes are often justified by the argument that homosexuality is 'un-African' or 'violates religious values'. Such deep-seated cultural and religious prejudices are difficult to challenge, and, if situated at faculty level, can impact the manner in which topics are taught. Challenging these attitudes at the faculty level is therefore an important imperative to teaching sexual orientation and gender identity. A directive from professional boards (such as the Health Professions Council of South Africa and the South African Nursing Council) could provide the necessary motivation and guidance to include sexual orientation and gender identity in existing curricula.

\section{Teaching by example}

We know that role modelling is an important way in which attitudes are fostered. ${ }^{[16]}$ Lecturers and clinical educators need to become LGBTIaffirming role models for students. To accomplish this, faculty should also be encouraged to learn about sexual orientation and gender identity, e.g. through continuing professional development (CPD) courses, departmental presentations, or journal clubs. Departments that have opportunities to include sexual orientation and gender identity topics can be approached and offered consultation to integrate these issues into their curriculum.

LGBTI students study in an institutional environment that is often heteronormative and homophobic, ${ }^{[17]}$ and should be supported by faculty staff. Information about LGBTI support services (e.g. through local LGBTI organisations) can easily be made available to all students. Staff should encourage the creation of an LGBTI student group, and make mentors available to individual students who need assistance with homophobic struggles. This can enable LGBTI students to contribute to conversations with heterosexual students where it is safe for them to do so, and can foster the individual interactions that are most effective in addressing homophobia. In my experience, students are often integral to introducing sexual orientation and gender identity into curricula by demanding to be taught about these topics. 


\section{Forum}

\section{Conclusion}

Addressing homophobia and remedying the effects of heteronormativity in health sciences curricula is complex. It requires awareness and attitude shifts from educators, which are prerequisites to introducing teaching about sexual orientation and gender identity to students. The curriculum provides multiple opportunities to incorporate such issues, but these opportunities will need to be framed in larger conversations about social inclusion and exclusion to successfully prepare health professions students to provide quality care to LGBTI people.

\section{References}

1. Müller A. Teaching lesbian, gay, bisexual and transgender health in a South African medical school: Addressing the gap. BMC Med Educ 2013;13:174.

2. Mayer KH, Bradford JB, Makadon HJ, Stall R, Goldhammer H, Landers S. Sexual and gender minority healt What we know and what needs to be done. Am J Pub Health 2008;98(6):989-995. [http://dx.doi.org/10.2105/ AJPH.2007.127811]

3. Aaron DJ, Markovic N, Danielson ME, et al. Behavioral risk factors for disease and preventive health practices among lesbians. Am J Pub Health 2001;91(6):972-975.

4. South African National Department of Health National Strategic Plan on HIV STIs and TB, 2012 - 2016. Pretoria: Department of Health; 2012. http://www.doh.gov.za/docs/stratdocs/2012/NSPfull.pdf (accessed 4 November 2012).
5. Lane T, Mogale T, Struthers H, McIntyre J, Kegeles SM. 'They see you as a different thing': The experiences of men who have sex with men with healthcare workers in South African township communities. Sex Transm Infect 2008;84(6):430-433. [http://dx.doi.org/10.1136/sti.2008.031567]

6. Wells H, Polders L. Gay and Lesbian People's Experience of the Health Care Sector in Gauteng. Research Initiative of the Joint Working Group conducted by OUT LGBTI Well-Being in collaboration with the UNISA Centre for Applied Psychology; 2006. http://www.out.org.za/index.php/library/reports\# (accessed 29 January 2015).

7. O'Hanlan K, Robertson P. Cabaj RP, Schatz B, Lock J, Nemrow P. Homophobia as a health hazard: Report of the Gay and Lesbian Medical Association. J Gay Lesbian Med Assoc 1997;1:25-39.

8. Cavanaugh RM. Obtaining a personal and confidential history from adolescents. J Adolesc Health Care 1986;7:118-122. 8. Cavanaugh RM. Obtaining a personal and confidential history from adolescents. J Adolesc Health Care 1986;:118-122.
9. Müller A. Barriers to health care for South African lesbian, gay, bisexual and transgender people. Poster presented at the 9th Public Health Association of South Africa (PHASA) Conference, $24-27$ September 2013, Cape Town, South Africa. 9th Public Health Association of South Africa (PHASA) Conference, 24 - 27 September 2013, Cape Town, South Africa.
Department of Justice. Patients' Rights Charter. http://www.justice.gov.za/vc/docs/policy/Patient\%20Rights\%20 Charter.pdt叉 (accessed 5 May 2014).
Chartment of Justice. Patient' Righ

1. Department of Health, KwaZulu-Natal. Batho Pele principles. http://www.kznhealth.gov.za/bathopele.htm (accessed 5 May 2014).

12. Sandfort TGM, Baumann LRM, Matebeni Z, Reddy V, Southey-Swartz I. Forced sexual experiences as risk factor for self-reported HIV infection among southern African lesbian and bisexual women. PLoS ONE 2013;8(1):e53552. [http://dx.doi.org/10.1371/journal.pone.0053552]

13. Lane T Raymond HF Dladla S, et al High HIV prevalence among men who have sex with men in Soweto, South Afric: Results from the Soweto Men's Study. AIDS Behav 2011:15(3):626-634. [http://dx.doi.org/10.1007/s10461-009-9598-y]

4. Müller A, Crawford-Browne S. Challenging medical knowledge at the source: Attempting critical teaching in the health sciences. Agenda: Empowering Women for Gender Equity 2013;27(4):25-34

15. Epprecht M. Heterosexual Africa? The History of an Idea from the Age of Exploration to the Age of AIDS. Athen, $\mathrm{OH}$ Olio

16. Yesidia MJ. Changes in physicians' attitudes toward AIDS during residency training: A longitudinal study of medical school graduates. J Health Soc Behav 1996;37:179-191.

17. Rose P. Review of Experiences of the Institutional Culture of the Medical Faculty, University of Cape Town. UCT UCT Students' Representative Council, 1995 